\title{
RETRACTED ARTICLE:
}

\section{Principle 8 - Surviving \\ vour professional duty}

On 6 April 2021 BDJ In Practice published in hardcopy and online an article entitled 'Principle 8 - Surviving your professional duty'. We hereby retract the article and confirm that it was published without the content being confirmed by, or a response sought from, the practice and practitioners asserted to be referred to therein. BDJ In Practice takes no position with respect of the accuracy of the contents and this retraction is by agreement with the practice and the practitioners asserted to be referred to therein. This article has been removed from the online version of $B D J$ In Practice.

Alfie Chan

Designated Safeguarding Officer in Practice and

Dental Advisor for Dental Training Ltd 
